\title{
Water in the Mogao Grottoes, China: where it comes from and how it is driven
}

\author{
HongShou $\mathrm{LI}^{1,2}$, WanFu WANG ${ }^{1,2 *}$, HongTao ZHAN ${ }^{1}$, Fei QIU ${ }^{1}$, QingLin GUO ${ }^{1,2}$, GuoBin ZHANG ${ }^{1,2}$ \\ ${ }^{1}$ The Conservation Institute of Dunhuang Academy, State Administration for Cultural Heritage, Dunhuang 736200, China; \\ ${ }^{2}$ Key Scientific Research Base of Conservation for Ancient Murals, Dunhuang Academy, State Administration for Cultural \\ Heritage, Dunhuang 736200 , China
}

\begin{abstract}
The Dunhuang Mogao Grottoes in China was designated as a world heritage site by UNESCO in 1987 and is famous for its cultural relics. Water is the most active factor that harms the relics in the caves as it damages the grotto murals and painted sculptures. Thus, determining the water sources and driving forces of water movement is a key issue for protecting these cultural relics. These issues have troubled relics protectors for a long time. In this study, the authors chose a representative cave in the Mogao Grottoes and, by completely sealing the cave to make a closed system, measured the water vapor from the surrounding rock. This was accomplished by installing a condensation-dehumidification temperature-humidity control system for the collection of water vapor. The results show that there is continuous evaporation from the deep surrounding rock into the cave. The daily evaporation capacity is determined to be $1.02 \mathrm{~g} /\left(\mathrm{d} \cdot \mathrm{m}^{2}\right)$. The water sources and driving forces of water movement were further analyzed according to the character of the water evaporation and by monitoring the temperature and humidity of the surrounding rock. It was found that the water vapor in the cave derives from phreatic water. Moreover, the yearly fluctuation of temperature in the surrounding rock and geothermal forces are the basic powers responsible for driving phreatic evaporation. Under the action of the yearly temperature fluctuations, decomposition and combination of bound water acts as a "pump" that drives phreatic water migration and evaporation. When the temperature rises, bound water decomposes and evaporates; and when it falls, the rock absorbs moisture. This causes the phreatic water to move from deep regions to shallow ones. Determining the source and dynamic foundation of the water provides a firm scientific basis for protecting the valuable cultural relics in the caves.
\end{abstract}

Keywords: the Silk Road; cultural heritage; surrounding rock; bound and phreatic water; thermodynamics

Citation: HongShou LI, WanFu WANG, HongTao ZHAN, Fei QIU, QingLin GUO, GuoBin ZHANG. 2015. Water in the Mogao Grottoes, China: where it comes from and how it is driven. Journal of Arid Land, 7(1): 37-45. doi: 10.1007/s40333-014-0072-y

With the opening of the Silk Road and development of cultural communication in ancient times, numerous temples were excavated in the form of caves along the Silk Road. These caves are representative examples of cave-style Buddhist temples. Today, these ancient caves remain well preserved and have become an important part of Buddhist heritage. Their good preservation is mainly thanks to the inland arid climate conditions in their location. However, under global climate warming and intensified human interference, sites of cultural heritage in arid lands, including the Mogao Grottoes, are suffering unprecedented losses (Ci, 2011).

Due to its long history, grand scale, rich content and state of preservation, the Dunhuang Mogao Grottoes was listed into the Directory of World Cultural Heritage by UNESCO in 1987 (Agnew, 2004). However, a survey found that about $50 \%$ of the wall paintings have suffered deteriorating diseases since their creation ca. 1600 years ago (Wang, 2005). Long-term

*Corresponding author: WanFu WANG (E-mail: wwanfu@hotmail.com) Received 2013-11-01; revised 2014-04-20; accepted 2014-08-10

(C) Xinjiang Institute of Ecology and Geography, Chinese Academy of Sciences, Science Press and Springer-Verlag Berlin Heidelberg 2015 
studies on the mechanisms of the diseases have shown that water is the most active factor in the deterioration of the murals and that most diseases involve the participation of water (Zhang et al., 1995; Guo, 2009).

Due to the action of water, salts are activated in the rock surrounding the caves and the plaster layers of the murals. This leads to the formation of various sorts of disorder and disease in the murals. For instance, due to the impact of humidity fluctuations, salts repeatedly recrystallize. This changes the structure of the plaster layer, causing particles to become loose and fall off and resulting in delamination (Zhang et al., 1995). Mural salt activity can also directly cause alkali efflorescence, which is also known as "mural cancer". Once this occurs, it is very hard to control (Cheng et al., 2005). Meanwhile, humidity and air temperature changes can cause the cave murals to chap and flake. In addition, the high humidity in the caves may cause the multiplication of a large number of bacteria, fungi, and other microbes (Yardım and Tunçoku, 2008; Sterflinger, 2010). This results in the structure deterioration of the plaster layers and painted sculptures (Herrera et al., 2008). Some microbes can even take organic pigments directly for nutrition and this leads to their mass propagation on the mural surface, forming serious mildew pollution (Wang et al., 2010).

Moisture problems have been the focus of efforts for the protection of cultural relics in caves (Liu et al., 2011). Wang et al. (2000) analyzed the geological environment of the Mogao Grottoes. Zheng et al. (2001) subsequently investigated the infiltration of irrigation water in the caves and measured transpiration from the tree-belt in front of the caves (Qin et al., 2002). In 2005, the current authors studied the water consumption and evapotranspiration mechanism in the tree-belt, and analyzed the influence of the water system on the microclimate in the Mogao Grottoes (Li, 2005, 2006; Li et al., 2009a, b). Guo et al. (2009) applied a high-density resistivity technique to detect the moisture status of the rock surrounding the Mogao Grottoes. Yang et al. (2009) also measured the water-salt spatial distribution in the rock. They concluded that some of the moisture came from the surrounding rock in the caves. Zhang et al. (2005) found that the breath of visitors also has a certain influence on the humidity in the caves. Zhang et al. (2006) investigated the environmental characteristics of the Daquan River which passes in front of the Mogao Grottoes. Yan et al. (2008) analyzed the moisture absorption-desorption pattern in the caves. More recently, Wang et al. (2010) studied the permeability of the rock surrounding the caves.

Although the water in the caves has been extensively studied by experts, there is confusion over the source of the moisture and the active mechanisms responsible for its presence. At present, a consistent conclusion has not been reached. To briefly sum up, there are four possible sources: (1) rainfall infiltration, (2) lateral seepage of irrigation water from the Daquan River, (3) atmospheric moisture (Guo, 2009), and (4) phreatic water (Li et al., 2011). However, each of these inferred sources is not supported by systematic and concrete evidence. Therefore, it is necessary to obtain a scientific understanding of the activity of water in the whole of the surrounding rock. Further research is clearly required to fundamentally determine the source of the water and the associated driving forces for water movement.

For the above objective, we conducted a study on the peripheral environment of the Mogao Grottoes to investigate moisture problems in 2005. At the top of the Mogao Grottoes, repeated experiments involving a greenhouse condensation method to simulate precipitation proved that precipitation could evaporate completely (Li et al., 2009c, 2010a, b, 2013). Also, it was found that there was a stable amount of water evaporation except for precipitation sources. Thus, it can be concluded that phreatic water is one of the important sources of moisture in the Gobi soil (Li et al., 2010a, 2011). In 2009, a greenhouse/air-conditioning method was used to measure the phreatic evaporation capacity of the Gobi, producing a result of $0.0219 \mathrm{~mm} / \mathrm{d}$ ( $\mathrm{Li}$ et al., 2010c). This new discovery on phreatic evaporation provides an important reference for the water source in the caves of the Mogao Grottoes.

Studies on phreatic evaporation and its related factors show that the environment is dynamic and depends on factors such as the intensity of the solar radiation, the temperature, air humidity gradient and geothermal activity. Of these, temperature change (which is affected by solar radiation) has the greatest 
influence on phreatic evaporation (Li et al., 2011). In relation to the caves, which largely avoid the effects of solar radiation, evaporation should be affected only by the air temperature and geothermal activity. However, conclusive evidence of whether there is phreatic evaporation has not yet been obtained. In this paper, with reference to the previously employed greenhouse experimental method, a closed system and artificial condensation method were used to investigate a chosen representative cave in the Mogao Grottoes. The research aims at exploring the source of water and the driving force of water movement, and providing scientific support for the protection of the precious cultural relics in the Mogao Grottoes. The work may also provide a reference for the protection of cultural relics in other grottoes along the Silk Road.

\section{Study area and cave}

The Mogao Grottoes $\left(40^{\circ} 02^{\prime} 13^{\prime \prime N}, 94^{\circ} 47^{\prime} 38^{\prime \prime} \mathrm{E}\right)$ is located in the southern margin of the Dunhuang basin, between the Sanwei and Mingsha mountains, and in the valley of the Daquan River. The caves, excavated
$30-40 \mathrm{~m}$ high in the conglomerate cliff on the west bank of Daquan River, can be roughly divided into three layers. The conglomerate belongs to the Jiuquan group, Pleistocene series $\left(\mathrm{Q}_{3}\right)$. The surrounding rock is dry and the water content is $0.5 \%-1.5 \%$ (Guo, 2009). The depth of phreatic water is over $200 \mathrm{~m}$. The climate is very dry with an annual precipitation of $42.2 \mathrm{~mm}$; the potential evaporation is $4,347.9 \mathrm{~mm}$. The solar radiation intensity can reach $1.1 \mathrm{~kW} / \mathrm{m}^{2}$ and the sunshine rate is $71 \%$. The annual average temperature is $11.3^{\circ} \mathrm{C}$. Also, the relative humidity is $38 \%$ and the annual average wind speed is $4.1 \mathrm{~m} / \mathrm{s}$ ( $\mathrm{Li}$ et al., 2009b).

The chosen experimental cave is Cave 72 (Fig. 1). It is located in the middle of the southern district and situated in the ground layer of the Mogao Grottoes. The cave is $9.6 \mathrm{~m}$ in depth. The cave type is arch crown and it was excavated during the Five Dynasties Period (AD 907-960). The length and width of the main room (Fig. 2) are both $6.6 \mathrm{~m}$. The height of the cave is $6.0 \mathrm{~m}$, the indoor surface area is $218 \mathrm{~m}^{2}$, and the volume is $233 \mathrm{~m}^{3}$. It is a representative of medium-sized caves in the Mogao Grottoes.

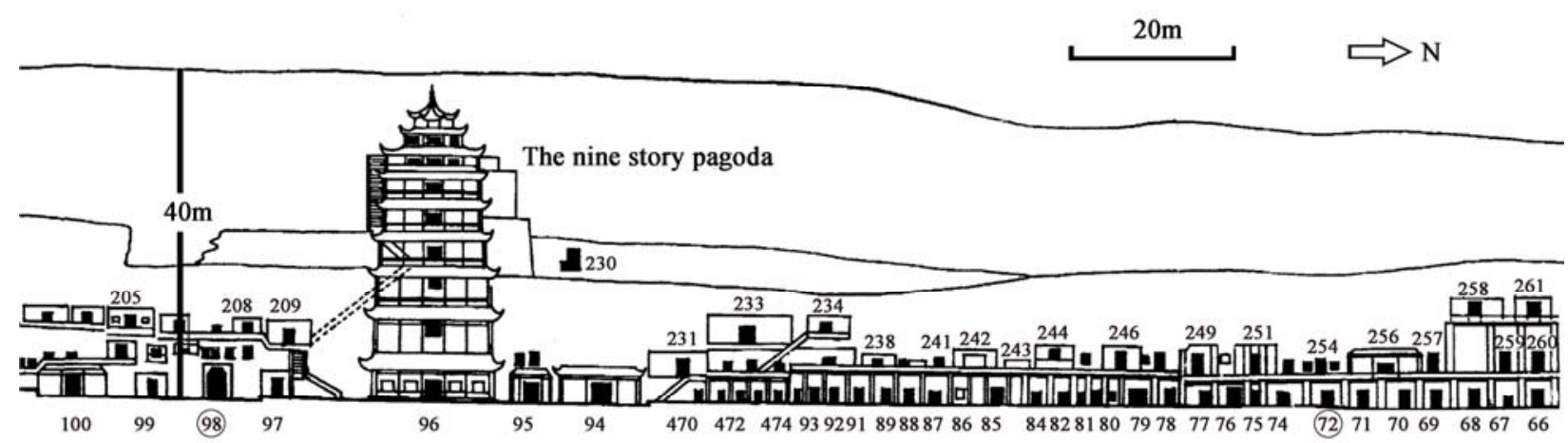

Fig. 1 A sketch highlighting the locations of Cave 72 and Cave 98 in the Mogao Grottoes

\section{Methods}

We applied a closed system and artificial condensation method, and collected a stable amount of evaporation coming from the surrounding rock in a closed cave. Then, according to the evaporation characteristics, temperature and humidity, we further determined the final source and dynamic foundation of the water in the cave.
Cave 72, as a representative cave of the Mogao Grottoes, was sealed on both sides of its aisle, which is a channel to the main room, by using plastic film (Fig. 2). Before the cave was closed, a specially designed condensation-dehumidification temperaturehumidity control (CDTHC) system was installed for this experiment. This system consists of an air-conditioner (Gree KFR-120LW 12568L AL-HN5) and a dehumidifier (DH-890C), as shown in Fig. 2. 


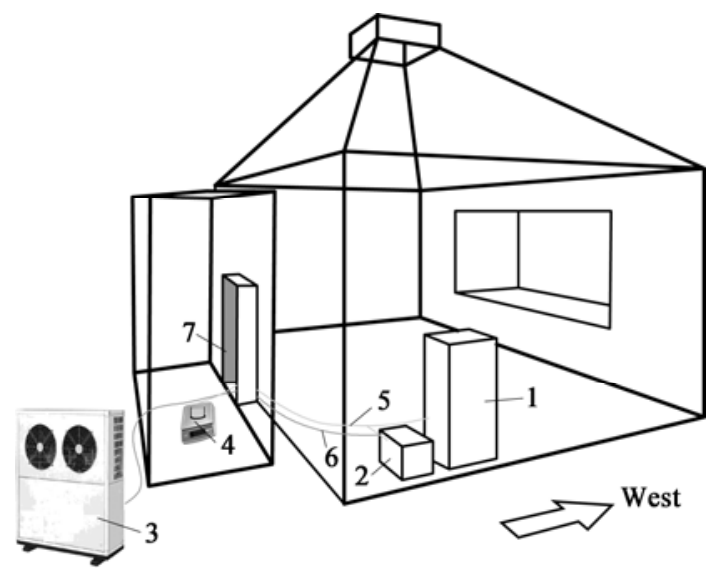

Fig. 2 A stylistic sketch map of Cave 72 and the specially designed condensation-dehumidification temperature-humidity control (CDTHC) system. 1, air conditioner; 2, dehumidifier; 3, air conditioning compressor; 4 , balance; 5 , condensate drain pipe; 6 , cooling circulation tube; 7 , sealing film.

The system was used to control the upper limits of temperature $\left(16^{\circ} \mathrm{C}-18^{\circ} \mathrm{C}\right)$ and humidity $(35 \%)$. It also condensed and collected water vapor every day (at 8 : $30 \mathrm{am}$ ) over a continuous period of 2 years. The results can be used to describe the basic features of the evaporation in the cave and help to analyze the main source of water.

The dynamic mechanism, which is responsible for moisture activity, has been the research focus of the water in the caves. For aiding the analysis, it is necessary to monitor temperature, relative humidity and absolute humidity in the surrounding rock. As there are precious murals on the walls of Cave 72 , steps were taken to reduce the experimental effects on the ancient cultural relics as far as possible. To reduce unnecessary repetition, the authors employed microenvironmental monitoring results obtained in 2006 from the rock surrounding Cave 98 (Guo et al., 2009).
These were combined with the condensed water data collected in Cave 72 to study the moisture activity in the surrounding rock and act as the basis of an analysis of the environment that causes the evaporation.

Cave 98 is located in the ground layer in the middle of the Mogao Grottoes (Fig. 1). It was excavated during the period of AD 914-935. The cave is $40 \mathrm{~m}$ from the top of the cliff surface and about $130 \mathrm{~m}$ from Cave 72. It has the same style but is bigger than Cave 72, with a depth of $21.6 \mathrm{~m}$. The large mural on the western wall has fallen off and been lost. At this location, the temperature was more stable and the range of annual temperature changes is lower than that in Cave 72. On the south end of the western wall, a series of holes were drilled using a drilling rig (TYQEJ100D). The holes were $90 \mathrm{~cm}$ high from the ground and located $138 \mathrm{~cm}$ away from the south wall at $0,10,30$, 62,95 and $125 \mathrm{~cm}$, respectively. In these holes we put temperature and humidity detection probes (produced by Vaisala, Finland), which were used to regularly determine the temperature and humidity on a weekly timescale. The temperature and humidity of the atmosphere outside the cave were recorded by weather stations in the Mogao Grottoes.

\section{Results}

\subsection{Evaporation characteristics}

After a continual collection of 2 years (2010-2012), $140.748 \mathrm{~kg}$ of condensed water vapor was taken in total. The quantity of condensate and the trend in annual change is shown in Fig. 3. The result reveals water evaporation from the surrounding rock into the caves. The average daily evaporation over a year is $222 \mathrm{~g} / \mathrm{d}$, which, in per unit area, equates to $1.02 \mathrm{~g} /\left(\mathrm{d} \cdot \mathrm{m}^{2}\right)$.

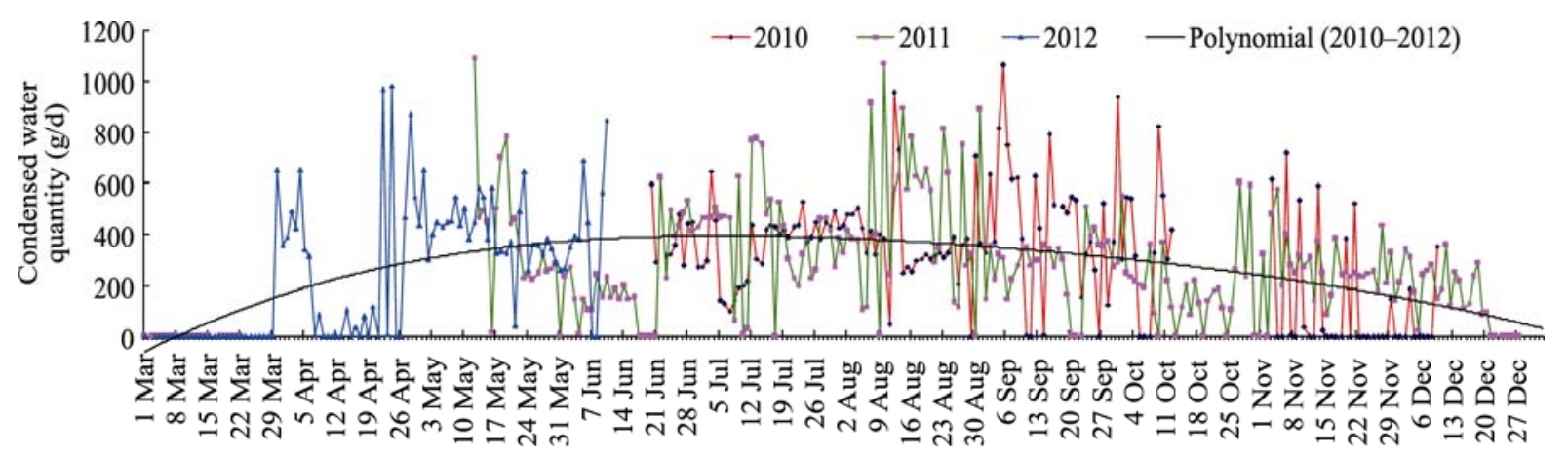

Fig. 3 The quantity of condensate collected on an annual basis (2010-2012) 
As it is affected by climate processes, evaporation is subject to a certain fluctuation. Therefore, evaporation along with the changes in temperature of the surrounding rock fluctuated on a yearly timescale. Evaporation occurred from April to November. During the evaporation period, there was stable continuous evaporation in the cave, which was uninterrupted at night. This was in contrast to the Gobi surface, where, on a daily timescale, the evaporation stopped in the night. Water evaporation in the cave can be characterized using functions such as the polynomials. A sinusoidal variation consistent with the phreatic evaporation characteristics found in the Gobi primarily suggests that the cave water comes from phreatic water (Li and Wang, 2014), which, of course, needs to be determined by analysis of the mechanisms responsible for the water dynamics of the surrounding rock.

\subsection{The diving force and activity mechanism}

The annual changes in the temperature, absolute humidity and relative humidity of the rock surrounding Cave 98 are shown in Fig. 4.

When the temperature is stable, the water vapor moves from areas of high humidity to areas of lower humidity ( $\mathrm{Li}$ et al., 2011). The distribution of the absolute and relative humidity in the rock surrounding the cave decreases progressively from deep to shallow depths (Fig. 4). Therefore, if only humidity is considered, water vapor should move outwards and evaporation should exist throughout the year. However, according to the monitoring results, there is evaporation only from April to December. This is mainly a result of the thermal activity of the water in the surrounding rock, which is dominated by temperature. The behavior is closely related to the temperature of the surrounding rock in the different strata and its changes in an orderly manner.

It is well known that on a microscopic scale, when the temperature is stable, decomposition of the bound water in the surrounding rock (i.e. hygroscopic water, film water and water of crystallization) is dynamically balanced by recombination due to adsorption of the surrounding air moisture. In the surrounding rock, when the temperature from the outside gradually rises, the bound water decomposes in progressively greater quantities, which breaks the original dynamic equilibrium of the moisture. This implies that decomposition is greater than combination, which results in vapor formation. Conversely, when the temperature falls, moisture adsorption is greater and bound water is formed.

At the end of January, the deep surrounding rock has a relatively high temperature and humidity compared to the shallow layer (Fig. 4), that is, the conditions are sufficient for water to move outwards. However, the water vapor that moves outwards continuously replaces the water that was lost last year by evaporation from the shallow surrounding rock. As the surface temperature of the surrounding rock begins to rise, decomposition of the bound water starts. However, the water vapor produced will not enter into the surrounding rock but instead directly evaporate into the atmosphere. Since the temperature rise at this time is small, the amount of water evaporated is very limited. Thus, even the CDTHC system could not detect the amount involved. However, according to the continuous monitoring of the absolute humidity in the sealed-up cave, the vapor could be observed to be slowly increasing.

In April, the pattern of the temperature changes in the surrounding rock at $0-125 \mathrm{~cm}$ appears to begin to reverse. That is, the temperatures of the shallower layers become higher than those of the deeper layers. In each layer, evaporation increases along with the continuous rise in temperature. So, more water vapor is produced through decomposition by heating in the shallow layer, and it will attempt to enter the deeper layers where the temperature is lower. However, as the water absorption capacity and water transportation in the soil are limited, a small amount of water vapor will be emitted outwards, forming vapor. Therefore, evaporation in the cave rises along with the gradually increasing temperature from April to August.

In the surrounding rock, the humidity of the deep layers is always larger than that of the shallower layers (Figs. 4a and b). This inhibits the migration of moisture into the rock to a certain extent, which is beneficial to the outward evaporation of water. After all, higher temperature and humidity are both sufficient conditions for water vapor to move to those areas which are cooler and less humid, but these are not necessary conditions ( $\mathrm{Li}$ et al., 2011). The actual direction in which the water moves depends on the relative differences in temperature gradient compared to 

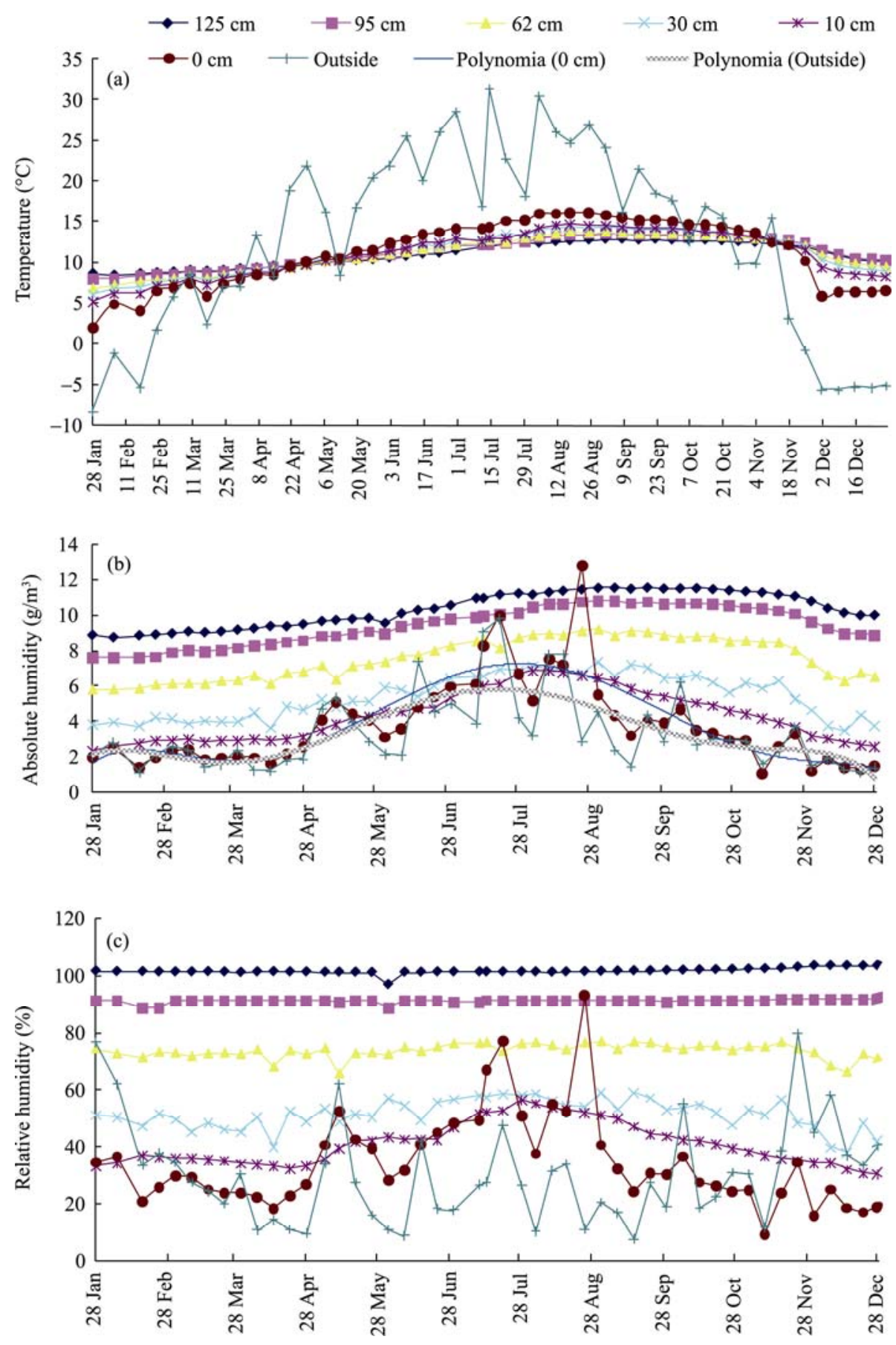

Fig. 4 Annual changes in the temperature, absolute humidity and relative humidity at different depths of the rock surrounding Cave 98 in 2006

humidity gradient. Higher temperature and slightly lower humidity, or higher humidity and slightly lower temperature, could make the moisture move to the outside. During April-August, the temperature and humidity conditions follow the former pattern and there should be much water vapor moving to the deep layers.
From August to December, the temperature gradually decreases and a positive gradient is set up from the shallow surrounding rock to the deep. According to the rock-soil properties, once the temperature drops, the decomposing of bound water in the soil is no longer faster than the binding of vapor on soil at the microscopic level, preventing the formation of vapor. 
Instead, moisture adsorption will immediately begin, which is the reverse of the process of water decomposition (Li et al., 2011). However, at that point, due to the delay in the heat (temperature) conduction to the deep surrounding rock (which is still in the increasing temperature phase), the "trapped" heat releases water vapor to supply the shallow layer.

The shallow rock layer is controlled by the falling temperature range. The quantity of rock that absorbs moisture is small and evaporation from the deep layers of the surrounding rock is relatively abundant. This can not only meet the needs of shallow absorption, but also form evaporation through the shallow surrounding rock.

From November to December, transformations in the temperature field within the layers have finished (Fig. 4) and the temperature in all layers starts to fall. The rock layers also start to absorb moisture and there is no evaporation. However, considering the temperature delay in the deeper surrounding rock, as indicated in the former analysis, the temperature is still rising (the deepest monitoring is too shallow for this process to be apparently detected in Fig. 4). Thus, the water vapor from decomposition is relatively abundant and it can still pass through the layer whose temperature is falling to form evaporation.

Generally, the depth of the yearly heterothermozone here is $20-30 \mathrm{~m}$ ( $\mathrm{Li}$ et al., 2010c). The vertical position of the cave is beyond this depth but considering the lateral influence of temperature and solar radiation acting on the cliff surface, the cliff body 20-30 m inwards should still be in the heterothermozone, as suggested by Fig. 4c. In any depth of the heterothermozone there are two transformations in a year, in which the temperature of the upper layer is higher than that of the lower layers, and then this alternates, so that the lower layer has higher temperature than the upper one. According to the rock surrounding the cave, the relationship between the shallow and deep rock is clear. Near the cliff surface, temperature changes present greater amplitudes. Even if the communication between the heat of the cave air and the outside atmosphere is not considered, the temperature of the surrounding rock also changes alternately. However, the opening of the cave and air communication will inevitably increase the change in temperature and therefore increase evaporation.

The rising and falling of the temperature directly relates to water decomposition (evaporation) and moisture absorption in the surrounding rock. These two properties relate to two completely different states. Water evaporation and absorption in the layers change in order with the temperature variation from the outside to the inside in an annual cycle. From April to December, there is a larger amount of evaporation on the whole. From January to March, although the moisture in the deep surrounding rock is constantly migrating outwards, all it does is supplementing the water lost by evaporation from the shallow surrounding rock. This absorbed water then forms vapor when it warms up the next year. Year after year, this cycle repeats itself. Under the alternating action of temperature, water decomposition and recombination in the surrounding rock acts as a "pump". It transships water from the deep surrounding rock to outer parts, and this deep moisture originates from phreatic water, just as in the Gobi soil ( $\mathrm{Li}$ et al., 2009c). Therefore, the cave water derives from phreatic water. As there is an evaporation mechanism, over a long period of time evaporation of the phreatic water (of which a certain part is in the form of film water that can dissolve salt) leads to a higher salt content in the shallow surrounding rock (Gou et al., 2009).

On a macroscopic level, geothermal effects cannot be ignored. Below the heterothermozone, where there is high temperature and humidity, there are sufficient conditions for phreatic water vapor to flow upwards under the action of the geothermal temperature field. A strong thermal effect can produce a saturated state $2.50 \mathrm{~m}$ under the Gobi surface throughout the year ( $\mathrm{Li}$ et al., 2011). Such a state is also apparent $1.25 \mathrm{~m}$ inside the rock surrounding the cave (Fig. 4). Therefore, a general upward movement of vapor exists and this water vapor converts to film water. However, tests on the deep surrounding rock show that the moisture content is no more than $1.5 \%$, a quantity that is not enough to form free water (Guo, 2009). The annual temperature variation in the heterothermozone affects the speed of moisture movement and the amount of evaporation, but the deep geothermal forces provide the most basic guarantee that water will migrate upwards. Therefore, the cave, its surrounding rock (het- 
erothermozone) and the deep underground layers form an "organic continuum", which forms the moisture continuously through its operation and evaporation.

\section{Discussion}

\subsection{Phreatic water continuum}

Many experiments show that in the Gobi soil which connects with the surrounding rock of caves, the main moisture comes from phreatic water (Li et al., 2009c, 2010a, b, 2013), but the buried depth of phreatic water is over $200 \mathrm{~m}$, and so the phreatic water cannot directly move to the soil surface as evaporation. Under the heterothermozone, the temperature and humidity gradients meet the conditions required for the application of Fick's Law (Fayer, 2000), and so moisture undergoes upward diffusive migration. The situation is relatively simple in this area. In the heterothermozone, the Fick formula is still suitable on a small scale. However, on a larger scale, the amount of moisture migration changes with temperature as a result of the yearly heat (temperature) conduction and migration in the heterothermozone. The soil itself is both a "source" and also a "sink". In related studies on unsaturated soil with generally and relatively higher water contents (i.e. liquid water is present), it is assumed that the amount of water studied does not change. In the heterothermozone, the temperature field changes with the seasons. This leads to the change in the direction of water migration and the presence of a small amount of measured evaporation moisture, which overflows on the land surface. This is contrary to the major direction of water migration. Due to the annual variation of the temperature field, suction in the surrounding rock also inevitably changes. At the same time, this causes vapor pressure and potential hydraulic fluctuations. The situation is thus more complicated in this area. In the shallow $125 \mathrm{~cm}$ of the surrounding rock or soil depths of less than $250 \mathrm{~cm}$, the relative humidity is $100 \%$. Therefore, soil water is a direct source of vapor diffusion here.

\subsection{Atmospheric moisture}

On 25 August 2006, there was a precipitation of $1.52 \mathrm{~mm}$ as recorded by weather stations in the Mogao Grottoes (Fig. 4). The humidity in the cave increased as a result of the precipitation. Actually, there are more humid weather processes which do not appear in the form of precipitation in the Dunhuang region. The outside humidity fluctuations also cause humidity changes inside the cave (Fig. 4). According to incomplete statistics, there is a humid weather process every 15 days or so in Dunhuang. However, precipitation and humid weather processes influence the humidity inside the surrounding rock only very slightly-they do not cause the inside humidity to rise significantly (Fig. 4). The outside humidity is lower than that inside or on the surface $(0 \mathrm{~cm})$ on the whole (see the polynomials in Fig. 4a). Therefore, no atmospheric water enters the surrounding rock as a result of the normal climate. As for the closed Cave 72, in which the effects of the atmosphere were eliminated, there still existed a stable amount of evaporation. Hence, the measured water evaporation came from phreatic water rather than atmospheric water or precipitation (Li et al., 2014).

\section{Conclusions}

By sealing up Cave 72 of the Mogao Grottoes and collecting condensation in an artificial method, we collected $140.748 \mathrm{~kg}$ of evaporated water within two years. The evaporation characteristics, temperature and humidity in the surrounding rock show that water vapor in the cave derives from phreatic water. Furthermore, the amount of phreatic evaporation is 1.02 $\mathrm{g} / \mathrm{d} \cdot \mathrm{m}^{2}$ and there must be a mechanism for its movement. The research on the water source and the forces driving water movement provided a scientific reference for the protection of the Mogao Grottoes and other cultural relics in the caves along the Silk Road.

\section{Acknowledgments}

We gratefully acknowledge funding for this work from the National Natural Science Foundation of China (41363009), the Gansu Province Science and Technology Plan (1308RJZF290) and a project of the Dunhuang Academy (201306).

\section{References}

Agnew N. 2004. Conservation of ancient sites on the Silk Road. In: The $2^{\text {nd }}$ International Conference on the Conservation of Grotto Sites. Los Angeles: Getty Publications, 3-30.

Cheng G Q, Su B B, Zhao L L, et al. 2005. Salting simulative test on wall painting plaster of Cave 85 in Mogao Grottoes. Dunhuang Research, (4): 62-66. (in Chinese)

Ci L J. 2011. Desertification of extra-arid desert. Chinese Science Bulletin, 56: 2616-2626. (in Chinese) 
Fayer M J. 2000. UNSAT-H Version 3.0: unsaturated soil water and heat flow model-theory, user manual and examples. Pacific Northwest National Laboratory, Washington, 331.

Guo Q L. 2009. Origin of water and salts responsible for wall paintings disease at Dunhuang Mogao Grottoes. PhD Dissertation. Lanzhou: Lanzhou University. (in Chinese)

Guo Q L, Wang X D, Xue P, et al. 2009. Research on spatial distribution and relations of salinity and moisture content inside rock mass of low-layer caves in Dunhuang Mogao Grottoes. Chinese Journal of Rock Mechanics and Engineering, 28(S2): 3769-3776. (in Chinese)

Herrera L K, Borgne S L, Videla H A. 2008. Modern methods for materials characterization and surface analysis to study the effects of biodeterioration and weathering on buildings of cultural heritage. International Journal of Architectural Heritage, 3: 74-91.

Li H S. 2005. The research in garden's water at Mogao Grottoes. Dunhuang Research, (4): 92-100. (in Chinese)

Li H S. 2006. The application of the dissipative structure theory to the water consumption of gardens at the Mogao Grottoes. Acta Ecologica Sinica, 26: 3454-3462. (in Chinese)

Li H S, Wang W F, Zhang G B, et al. 2009a. The primary proof - testing of the evapotranspiration dissipative structure in the extreme dry area. Research of Soil and Water Conservation, 16: 200-204, 209 (in Chinese)

Li H S, Wang W F, Zhang G B, et al. 2009b. The influence of water system on microclimate of Mogao Grottoes. Dunhuang Research, (3): 110-13. (in Chinese)

Li H S, Wang W F, Guo Q L, et al. 2009c. Mechanism analysis on condensation water in arid area at Mogao Grottoes. Acta Ecologica Sinica, 26: 3198-3205. (in Chinese)

Li H S, Wang W F, Zhan H T. 2010a. New judgment on the source of soil water in extremely dry zone. Acta Ecologica Sinica, 1: 1-7.

Li H S, Wang W F, Zhang G B. 2010b. Moisture interaction between soil and atmosphere in extreme dry area. Journal of Earth Science Environment, 32: 183-188. (in Chinese)

Li H S, Wang W F, Zhang G B, et al. 2010c. Measurement of deep buried phreatic water evaporation in extremely arid area. Acta Ecologica Sinica, 4: 6798-6803. (in Chinese)

Li H S, Wang W F, Zhang G B, et al. 2011. GSPAC water movement in extremely dry area. Journal of Arid Land, 3: 141-149.

Li H S, Wang W F, Zhan H T. 2013. Applying isolation method study soil water source in the extreme dry area. Arid Land Geography, 36: 92-100. (in Chinese)

Li H S, Wang W F. 2014. Determination and analysis of phreatic water evaporation in extra-arid dune region. Acta Ecologica Sinica, 34: $116-122$.
Li H S, Wang W F, Zhan H T, et al. 2014. Application of a greenhouse air-conditioning method to simulate take-back of rainfall in an extremely arid area. Acta Ecologica Sinica. doi: 10.5846/stxb201301290185. (in Chinese)

Liu R Z, Zhang B J, Zhang H, et al. 2011. Deterioration of Yungang Grottoes: diagnosis and research. Journal of Cultural Heritage, 12: 494-499.

Qin Q S, Zheng C X, Wang W F, et al. 2002. An estimate of the limits of transpiration for irrigation trees in front of the grottoes. Dunhuang Research, (4): 97-101. (in Chinese)

Sterflinger K. 2010. Fungi: their role in deterioration of cultural heritage. Fungal Biology Reviews, 24: 47-55.

Wang J Y. 2005. The investigation on the current condition of Mogao Grottoes and the classification of diseases in exist. Dunhuang Research, (6): 94-98. (in Chinese)

Wang X X, Zhang M Q, Zeng Z Z, et al. 2000. Engineering properties of surrounding rocks of Mogao Grottoes at Dunhuang. Chinese Journal of Rock Mechanics and Engineering, 19: 756-761.

Wang X D, Guo Q L, Li Z X, et al. 2010. Research on permeability of surrounding rock at Dunhuang Mogao Grottoes. Rock and Soil Mechanics, 31: 3139-3144. (in Chinese)

Wang W F, Ma X, Ma Y T, et al. 2010. Seasonal dynamics of airborne fungi in different caves of the Mogao Grottoes, Dunhuang, China. International Biodeterioration \& Biodegradation, 64: 461-466.

Yan L, Zhang H Y, Lu Q F, et al. 2008. Isothermal model for moisture adsorption and desorption of plaster layers of wall-paintings inside grottoes. Dunhuang Research, (6): 58-62. (in Chinese)

Yang S L, Wang X D, Guo Q L. 2009. Preliminary analysis of moisture distribution in cliff rocks of the Mogao Grottoes in Dunhuang. Hydrogeology and Engineering Geology, 35: 94-97. (in Chinese)

Yardım Bülent, Tunçoku S S. 2008. Dampness problems in a historic house in İzmir, Turkey. International Journal of Architectural Heritage, 3 : 1-23.

Zhang M Q, Zhang H Y, Zeng Z Z, et al. 1995. The mechanisms of efflorescent disaster of wall-paintings in Mogao Grottoes. Journal of Lanzhou University: Natural Sciences, 31: 96-101. (in Chinese)

Zhang G B, Xue P, Hou W F, et al. 2005. The study on micro-environment of the cave affected by the visitors of the Mogao Grottoes. Dunhuang Research, (4): 83-86. (in Chinese)

Zhang M Q, Wang X D, Jia N, et al. 2006. Analysis of water environment characteristics of the Daquan River in Dunhuang. Journal of Lanzhou University (Natural Sciences), 42: 7-10. (in Chinese)

Zheng C X, Qin Q S, Wang W F. 2001. A study on the water infiltration of the woodland nearby the caves of Dunhuang Mogao grottoes. Dunhuang Research, (3): 173-177. (in Chinese) 